\title{
Spatial biomonitoring of persistent organic pollutants in Iran: a study using locally produced butter $\dagger$
}

\author{
Amirali Jafari, Claudia Moeckel and Kevin C. Jones* \\ Received 5th February 2008, Accepted 28th April 2008 \\ First published as an Advance Article on the web 21st May 2008 \\ DOI: 10.1039/b802061b
}

Butter is a readily collected, integrative and inexpensive sampling matrix for the spatial mapping of persistent organic pollutants (POPs) at the national or regional scale. As air-plant-animal transfers generally supply the POPs reaching butter lipid, this study used butter for an initial evaluation of the occurrence, levels and distribution of POPs (selected organochlorine pesticides and PCBs) in Iran, a country for which very little information on usage, emissions and environmental burdens of these compounds exists. Fifty samples from rural and urban areas, in the north, west and central regions of the country were collected from local farms in spring 2007. Concentrations of $p, p^{\prime}$-DDT and $p, p^{\prime}$-DDE varied widely by a factor of $\sim 1000$ and $\sim 370$ ( $8450 \mathrm{pg} \mathrm{g}^{-1}$ lipid and $46800 \mathrm{pg} \mathrm{g}^{-1}$ lipid on average). The highest levels, found mainly in urban areas in the centre of the country, were amongst the highest reported in the world. PCB concentrations ( $4320 \mathrm{pg} \mathrm{g}^{-1}$ lipid on average) varied by a factor of $\sim 160$ and were highest close to urban centres and lowest in the rural northwest. Although Iran is not known for widespread PCB usage in the past, concentrations were higher than a 'global average' reported in a butter survey in 2001. This simple sampling approach could be adopted in other regions where cows graze, as part of an initial screening to help meet obligations under the Stockholm Convention.

\section{Introduction}

Spatial variations in persistent organic pollutants (POPs) need to be assessed on the national, regional and global scale, to evaluate the effectiveness of international treaties designed to eliminate or reduce their release to the environment. Signatory countries to the Stockholm Convention are required to produce a national implementation plan (NIP), to identify and reduce sources, and to monitor for effectiveness in reducing ambient levels and human/wildlife exposure. ${ }^{1}$ Under the United Nations Environment Programme (UNEP) a global series of regional reports was produced, which-where possible-summarised measured ambient data in order to evaluate regional hotspots etc. The reports for some regions were relatively 'data rich' (e.g. Europe, North America and Asia). ${ }^{2-4}$ In contrast, there is still a lack of information for the Middle East. ${ }^{5}$

In 2003, UNEP produced a report on the objectives and possible design of a Global Monitoring Network for POPs. ${ }^{6}$ Mindful of the costs of sampling and analysis, the report considered the environmental and biological matrices which could be used to perform rapid reconnaissance and assessment of POP levels and distributions. Often there may be interest in an initial, relatively cheap and easy evaluation of a country or region, which has little or no published data or 'in house' expertise for environmental sampling and analysis. ${ }^{6}$ Air sampling, often using innovative passive sampling techniques, can give useful

Centre for Chemicals Management and Environmental Science Department, Lancaster Environment Centre, Lancaster, UK LA1 4 YQ

$\uparrow$ Electronic supplementary information (ESI) available: Maps of Iran, showing key features of the country, includes the distribution of pollutants and sites selected for sampling. Tables provide sampling data. See DOI: 10.1039/b802061b information to compare with other regions where data are more plentiful. $^{6,7}$ However, even passive air sampling requires local operatives for the samplers and return visits to the sites.

Iran is a country for which very little information on POPs exists. In 2007, the opportunity to visit and conduct a spatial survey of Iran arose. Less than 6 months and less than $\$ 10000$ was available to conduct a study as part of a Masters degree. This figure had to include the flights from the UK to Iran, internal travel in Iran, sampling and analytical costs. Consideration was therefore given to how data could be obtained cheaply, quickly and easily from a single visit to the country. Deployment of passive air samplers was not an option, because they would require a return visit. Butter was selected as the sampling medium instead. Several studies have used butter to assess environmental contamination with POPs. ${ }^{8-12}$ It is a convenient and relatively uniform monitoring medium and reflects the regional and global scale distribution of POPs. ${ }^{89}$ The high lipid content of butter (typically $\sim 80 \%$ fat) provides relatively high concentrations of most POPs, with good detection limits and relatively easy analysis. ${ }^{12}$ Residues in butter reflect the occurrence of POPs in the cow's feed (typically pasture grass), which in turn is contaminated via atmospheric deposition of diffusive airborne POPs. Supporting studies show the quantitative link between air concentrations, herbage concentrations, and milk fat concentrations. ${ }^{13,14}$ PCBs and other semivolatile persistent, bioaccumulatory organic contaminants reach human tissue primarily via dietary intake of meat and dairy products (i.e., milk, butter, and cheese) and fish. Cows are therefore one of the main suppliers of these chemicals to humans. ${ }^{13,14}$

This paper describes a simple survey, but illustrates how useful information about chemical usage and distribution can be obtained on a national scale from such an exercise. 
Fig. 1 presents a map of Iran and its geographical region, showing the major cities and the sample locations. Iran has a population of 70 million people and a land area of 1650000 $\mathrm{km}^{2}$. Its mixed topography ranges from mountainous areas in the west, northwest, and north to flat areas in the east, centre and southeast. Iran's climate is mostly arid or semiarid, with more humid areas in the coastal plains of the Caspian Sea, the Persian Gulf and the Gulf of Oman. Economically, the country's major manufactured products are petrochemicals, steel and copper products. Agriculturally, about $20 \%$ of the land in Iran is arable. The main food-producing areas are in the north (Caspian region) and northwest. Supplementary Figures SI-1-3† give details of these features of the country.

\section{Experimental}

\section{Sample collection}

In total, 50 'home made' (local) and 3 commercial butter samples were collected during April and early May 2007 from 12 of the 30 provinces of Iran (see Fig. 1 and Figure SI-4† for more details). The provinces sampled (in the north, northwest and centre) are the areas where most of the population of the country lives and where most of the industry is based. 'Home made' samples derive from: (1) farmers in some rural areas who raise a few cows to supply their own dairy products and then sell their extra products to local people at their houses; (2) farmers in some parts of the country, especially the north, who make various foodstuffs in their homes, and then sell their excess dairy products - including butter - in open markets; (3) dairy shops located in suburbs of industrial cities which either make or purchase home made butter from farmers in their vicinity. Table SI- $1 \uparrow$ provides details of the sample locations.

Samples ( $200 \mathrm{~g}$ each) were obtained, placed in hexane-rinsed aluminium foil, transferred to labelled PE zip-lock bags and sealed quickly to avoid contamination. They were placed in a cool box for the day and frozen. Three commercial butter samples were also purchased from supermarkets. The samples were stored and transported frozen to Lancaster University until analysis. During the butter collection, farmers/sellers were interviewed regarding the type and origin of the cows' food and feed supplements in order to ensure that samples were obtained for which the cows were fed with local products only.

\section{Extraction and clean-up}

About $1.5 \mathrm{~g}$ of butter was weighed into a pre-weighed (clean and previously solvent rinsed) $250 \mathrm{ml}$ flask. Sub-samples were taken from the centre of the butter portions, to minimize the influence of any possible surface contamination from the packing. Then $\sim 5 \mathrm{~g}$ of anhydrous sodium sulfate was added. Approximately $50 \mathrm{ml}$ of hexane was added and the solution heated on a steam bath until the butter dissolved in the hexane, it was then cooled. In order to determine the lipid content, approximately $20 \%$ of the extract (exact weights of sub-samples recorded) were transferred to a pre-weighed vial, evaporated until dryness and re-weighed. On average the samples contained $78 \%$ lipids with a relative standard deviation of $10 \%$. The remaining sample in the flask
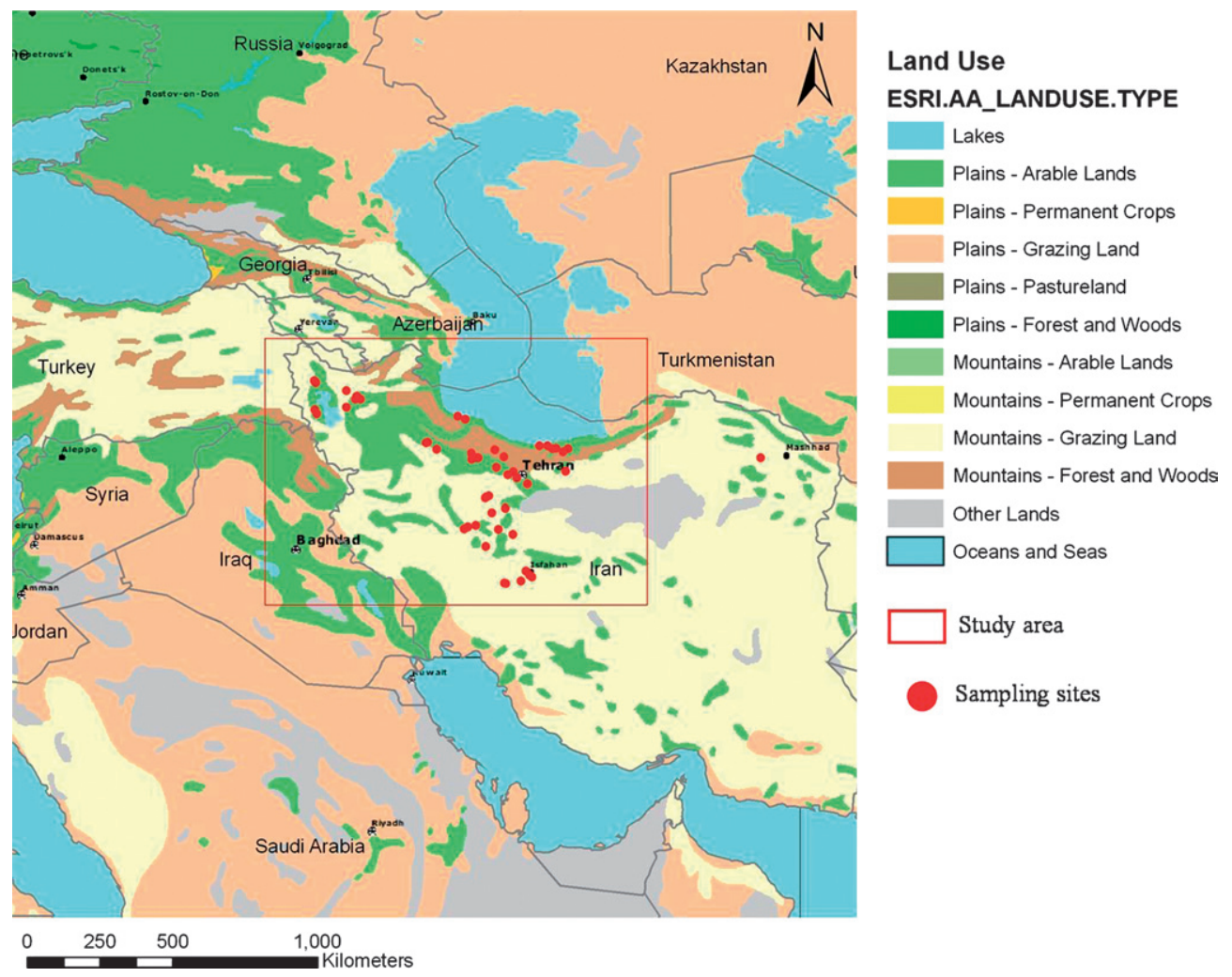

Fig. 1 Location map of Iran and the sample sites (shown as red dots). (The identification numbers of the sample sites are shown in Figure SI-4 $\uparrow$ in a more detailed map.) 
was spiked with $25 \mu \mathrm{l}$ recovery standards containing ${ }^{13} \mathrm{C}_{12^{-}}$ labelled PCBs (PCB-28, 52, 101, 138, 153, 180, 209) and evaporated in a rotary evaporator to $\sim 5 \mathrm{ml}$.

The extract was first cleaned on a $25 \mathrm{~mm}$ i.d. column, packed with $9 \mathrm{~g}$ of acidified silica gel $(9: 2$ (w/w) activated silica : concentrated sulfuric acid) between two thin layers of anhydrous sodium sulfate. The sample was applied quantitatively to the column and eluted with $\sim 200 \mathrm{ml}$ hexane. It was then evaporated to $c a .3 \mathrm{ml}$ on the rotary evaporator and blown down to $\sim 0.5 \mathrm{ml}$ under a gentle nitrogen stream. A final clean-up was performed on a Biobeads S-X3 gel permeation chromatography (GPC) column using a hexane-dichloromethane mixture $(1: 1)$ as the mobile phase. The first $16 \mathrm{ml}$ of the eluate was discarded as it contained lipids; the following fraction of $25 \mathrm{ml}$, containing the target compounds, was collected and reduced to about $0.5 \mathrm{ml}$ in a $40 \mathrm{ml}$ vial under a gentle nitrogen stream. The sample was transferred to a small tulip GC vial, with several washings and $25 \mu \mathrm{l}$ of dodecane, containing PCB-30 and ${ }^{13} \mathrm{C}_{12}$ PCB-141 as internal standards added as keeper solvent to reduce analyte losses upon evaporation. The final solution was then reduced to $25 \mu \mathrm{l}$ and analyzed by GC-MS.

\section{Gas chromatography}

The samples were analysed for a total of 44 PCBs (congeners 18, $22,28+31,41+64,44,49,52,54,70,74,87,90+101,95,99$, $104,105,110,114,118,123,132+153,138,141,149,151,155$, $156,157,158,167,170,174,180,183,187,188,189,194,199$, 203 ) and OC pesticides (hexachlorobenzene (HCB), $\alpha-$ and $\gamma$-chlordane, $p, p^{\prime}$-DDD, -DDE, -DDT, $o, p^{\prime}$-DDD, -DDE, -DDT) by GC-MS on a Finnigan Trace operated in positive electron ionisation mode using selected ion monitoring. Analysis of $\alpha-, \beta-, \gamma-$ and $\delta-\mathrm{HCH}$ was performed on the same instrument operated in negative chemical ionisation mode with ammonia as the reagent gas using selected ion monitoring mode. A CP-SIL $8 \mathrm{CB}$ column was used ( $50 \mathrm{~m}, 0.25 \mathrm{~mm}$ i.d., Varian) with helium as the carrier gas at a constant flow of $1 \mathrm{ml} \mathrm{min}^{-1}$. Quantification of target and recovery compounds was based on a set of seven calibration standards run at the beginning and end of each batch of samples.

\section{Chemical sources}

Hexane (Fisher Scientific) was of HPLC grade and dichloromethane (Fisher Scientific) was of GLC-pesticide residue grade. Silica gel (Merck 60, 0.063-0.200 mm) was activated at $450{ }^{\circ} \mathrm{C}$ overnight in a muffle furnace for the acid silica chromatography. Anhydrous sodium sulfate $(\mathrm{BDH})$ was baked out at $450{ }^{\circ} \mathrm{C}$ overnight, and all sorbents were stored in sealed containers. All Pasteur pipettes, GC vials, and $40 \mathrm{ml}$ small vials were baked out overnight to avoid any possible contamination.

\section{Quality control/quality assurance (QA/QC)}

All analytical procedures were monitored using quality assurance and control measures. Six laboratory blanks consisting of sodium sulfate were extracted and analysed in the same way as the samples. Method detection limits (MDLs) were derived from the blanks and quantified as 3 times the standard deviation of the mean blank concentrations. MDLs ranged between 30 and
110 pg sample ${ }^{-1}$ for PCBs and between 50 and 150 pg sample ${ }^{-1}$ for OC pesticides, corresponding to approximately $30-110 \mathrm{pg} \mathrm{g}^{-1}$ lipid and $50-150 \mathrm{pg} \mathrm{g}^{-1}$ lipid, respectively. Peaks were only integrated when the signal-to-noise ratio was $\geq 3$; otherwise, they were considered not detected. Average recoveries were $76 \%$ for ${ }^{13} \mathrm{C}_{12}$ PCB 28, 78\% for ${ }^{13} \mathrm{C}_{12}$ PCB 52, 75\% for ${ }^{13} \mathrm{C}_{12}$ PCB $101,77 \%$ for $13 \mathrm{C}_{12}$ PCB $138,80 \%$ for ${ }^{13} \mathrm{C}_{12}$ PCB 153 , and $79 \%$ for ${ }^{13} \mathrm{C}_{12}$ PCB 180, with relative standard deviations between $17.6 \%$ and $18.9 \%$ for all recovery compounds. Reported values are corrected for blanks but not for recovery. Instrument performance was monitored using quality control standards after every six samples analysed on the instrument.

\section{Results and discussion}

\section{Introductory remarks}

Cows in Iran typically graze on grass and lucerne, and receive some supplements, such as cereal-based products (e.g., oatmeal, maize, waste bread, and wheat bran), oilseed bran, root vegetables and soya. Farmers in the north may use rice stems and rice bran as supplements. Root crops and cereal grains typically contain very low concentrations of POPs. The general pathway, contaminating butter with these compounds, is therefore believed to be: air - deposition to above-ground plant parts ingestion by the cow - absorption - and transfer to milk fat. ${ }^{8,13,14}$ This may be supplemented by POPs bound to ingested soil, and by low levels of these pollutants in the cereal grain and root crop feed supplements - a pathway that may play a significant role for pesticides in areas where they are used in agriculture. The full organochlorine pesticide and PCB data sets are given in Tables SI-2 and SI-3†, respectively.

\section{$\sum$ DDTs}

The most frequent DDT isomers and metabolites detected were $p, p^{\prime}$-DDE (100\%), $p, p^{\prime}$-DDT $(96 \%)$, and $p, p^{\prime}$-DDD $(94 \%)$. Concentrations of $\sum \mathrm{DDT}\left(p, p^{\prime}\right.$-DDT, $o, p^{\prime}$-DDT, $p, p^{\prime}$-DDE, and $p, p^{\prime}$-DDD) varied between 660 and $607000 \mathrm{pg} \mathrm{g}^{-1}$ over the study area with lowest levels detected in the northwest and highest levels in central Iran (see Fig. 2a). On average, concentrations in Iranian butter samples were considerably higher than those found in a global study. ${ }^{8}$ This result agrees with the relatively high levels determined in human milk samples collected in Tebriz (northwest Iran) in 1991, compared to other countries. ${ }^{15,16}$ In the present study, some of the samples with high DDT levels were from urban areas. This may be linked to indoor spraying, used in the past to control vector-caused diseases such as malaria. The central region is primarily agricultural, with wheat, barley and cotton as the typical crops. Here, the high burdens clearly indicate extensive usage of DDT mixtures as pesticides, but they were dominated by $p, p^{\prime}$-DDE, suggesting older residues/past usage. The $p, p^{\prime}$-DDT to $p, p^{\prime}$-DDE ratio provides an indication of how recently DDT formulations have been released to the environment, with the ratio decreasing over time as the DDT degrades. To allow for a sensible interpretation of DDT/DDE ratios it is necessary to take into account that typical values vary considerably between different environmental media. ${ }^{17}$ Ratios in soil or sediment, and therefore also in the air and in vegetation, are usually significantly higher than those in animal products 

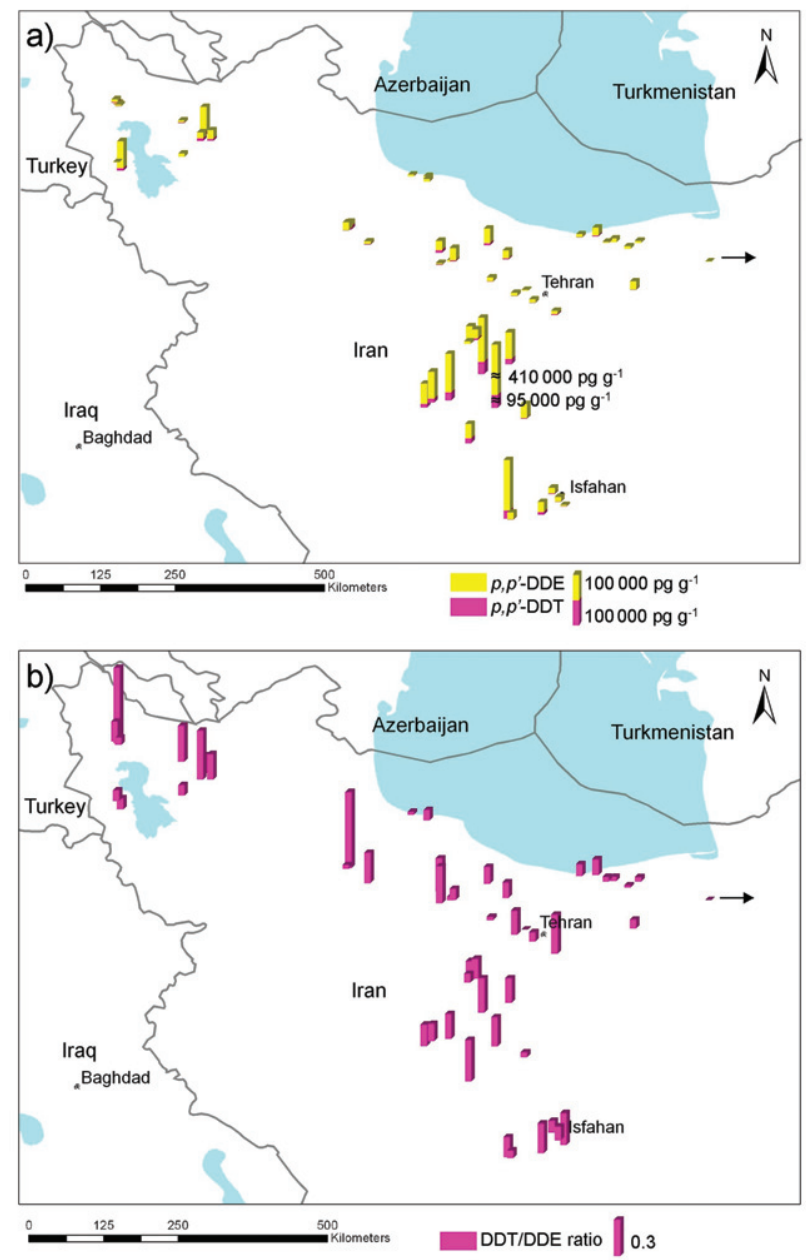

Fig. 2 DDT and DDE in Iranian butter samples: a) $p, p^{\prime}$-DDT and $p, p^{\prime}$-DDE concentrations (b) DDT/DDE ratios.

because metabolic conversion of DDT into DDE or DDD by soil microorganisms is generally much slower than by mammals. ${ }^{17,18}$ Moreover, DDE is excreted from the body by lactation at a higher rate than DDT, resulting in a relative enrichment of DDE in the milk. ${ }^{19}$ The highest and lowest DDT/DDE ratios in the current data set are 0.62 and 0.02 in the northwest and north, respectively, a large variation (see Fig. 2b). In some samples, mainly from the northwest of the study area where the risk of malaria is very low, high DDT/DDE ratios of up to 0.62 suggest fresh application of DDT. The average DDT/DDE ratio for all Iranian samples was 0.15 , slightly higher than the mean ratio $(0.09)$ obtained in a global butter survey conducted around $2000^{8}$ (see Table 1).

\section{Hexachlorocyclohexane ( $\mathrm{HCH})$ isomers}

$\mathrm{HCHs}$ have been commercially available as either technical $\mathrm{HCH}$, typically consisting of $60-70 \% \alpha-\mathrm{HCH}, 5-12 \% \beta-\mathrm{HCH}$, $10-12 \% \gamma-\mathrm{HCH}, 6-10 \% \delta-\mathrm{HCH}$ and $3-4 \% \varepsilon-\mathrm{HCH},{ }^{20}$ or as lindane (pure $\gamma-\mathrm{HCH}$ ). The vast majority of $\mathrm{HCH}$ used today is in the form of the $\gamma$ isomer. $\beta-\mathrm{HCH}$ is the most metabolically stable and predominant isomer accumulating in human tissues. Fig. SI- $5 \dagger$ shows the spatial distribution of $\mathrm{HCHs}$ detected in the Iranian butter samples. The variation between highest and lowest concentrations of individual isomers in butter samples (above MDL) was 124 times for $\alpha-\mathrm{HCH}, 112$ for $\beta-\mathrm{HCH}$, and 86 for $\gamma$ $\mathrm{HCH}$. The highest concentrations of each isomer were found in the centre of the country. High $\alpha / \gamma-\mathrm{HCH}$ ratios are often used as evidence of current technical $\mathrm{HCH}$ application. The mean value of this ratio for butter samples from Iran was $\sim 1$; lower than in India, China, and Philippines. ${ }^{8}$ Higher ratios of $\sim 5$ and 3, respectively, were recorded in central parts of Iran. However, as they coincide with high levels of $\beta-\mathrm{HCH}$, this suggests rather past than current usage of technical mixtures at these sites (in some samples $\beta-\mathrm{HCH}$ is the most abundant isomer despite its relatively low percentage in technical $\mathrm{HCH}$ ) ${ }^{20}$ Only in a few samples from the north did relatively high $\mathrm{HCH}$ concentrations, dominated by the $\gamma$-isomer, indicate a more recent use of products containing lindane.

\section{Hexachlorobenzene (HCB)}

Although HCB does not appear to have been used as a pesticide in Iran, it was widely detected, ranging between 450 and $4900 \mathrm{pg}$ $\mathrm{g}^{-1}$ (see Fig. SI- $6 \dagger$ ). The range of values (factor of $\sim 11$ ) was lower than for other organochlorine compounds studied in this survey and the mean Iranian concentration was slightly higher than the

Table 1 Comparison of the results of this survey for locally produced butter samples from Iran and the results of Kalantzi et al. ${ }^{8}$ in 23 countries across the world

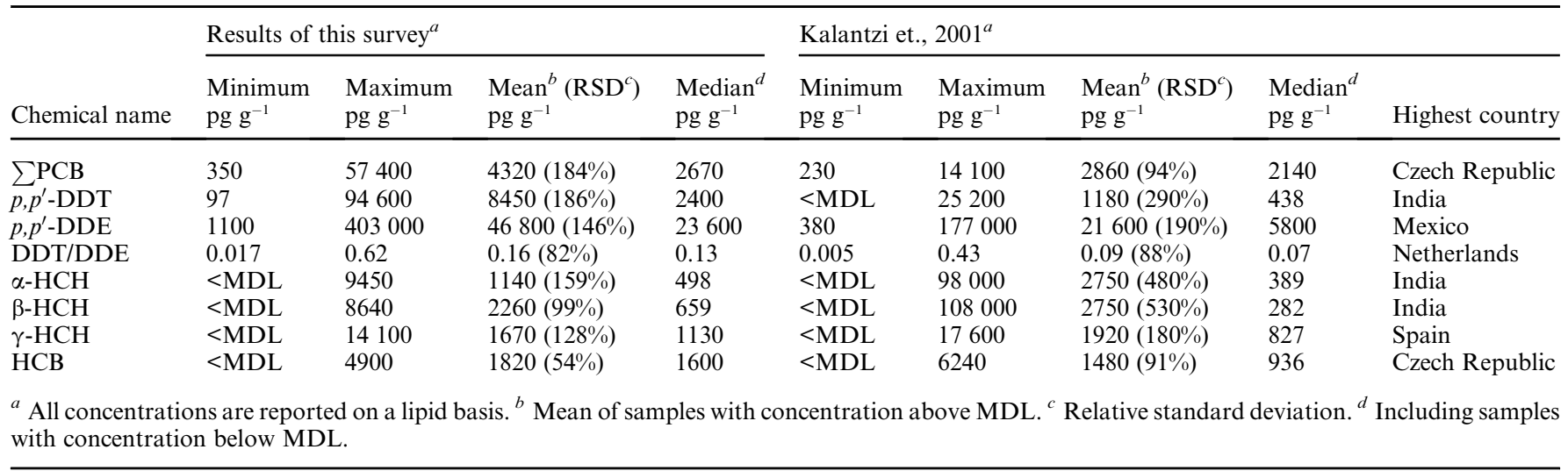


average found in a global study ${ }^{8}$ (Table 1). The relative uniformity of HCB in the butter samples is consistent with ambient global levels being largely controlled by secondary sources and environmental recycling. ${ }^{21}$ This has been observed previously for air samples from Europe. ${ }^{22}$

\section{Chlordanes}

Chlordanes were below MDL (corresponding to $c a$. $50 \mathrm{pg} \mathrm{g}^{-1}$ lipid) in all of the butter samples from Iran.

\section{PCBs}

$\sum \mathrm{PCB}$ concentrations varied between 350 and $57400 \mathrm{pg} \mathrm{g}^{-1}$ (a factor of $\sim 160$ ) (Fig. 3; Table 1) with the highest concentrations found in samples from Mazandaran province in the north and from large cities such as Tehran, Isfahan and Arak. These are among the most industrialised and densely populated parts of the country. Lowest values were found in Chongharaloy (Urmia) and Dasht e Abi (Ghazvin) — rural/remote areas. Broadly, PCB concentrations declined on an urban-rural gradient. However, the gradient was sharper for high molecular weight PCBs than for lower chlorinated congeners: the high-to-low ratios between samples from Isfahan, Arak and Tehran as urban sites and corresponding rural sites are 2.5, 1.7 and 4.0 for PCB-28 +31 and $4.4,4.3,4.3$ for PCB-180, respectively. Therefore the ratio between PCB congeners 180 and $28+31$ is usually higher in the vicinity of sources than in areas further away (see supporting information, Table SI-3†). This is consistent with urban-rural gradients that have been reported previously for PCBs in air. ${ }^{23,24}$ Given the higher particle deposition rates in urban areas compared to rural ones, this phenomenon can be attributed to the generally decreasing vapour pressure of PCBs with increasing molecular weight, ${ }^{24}$ resulting in increasing particle-air partition coefficients and decreasing potential to revolatilise once the chemical has been trapped, e.g. in plant surface waxes. The unusually high ratio between high and low chlorinated PCBs in Ghaemshahr (north, sample 24) may be caused by cows ingesting feed or soil/sediments that were contaminated directly by PCB containing products rather than airborne pollutants.

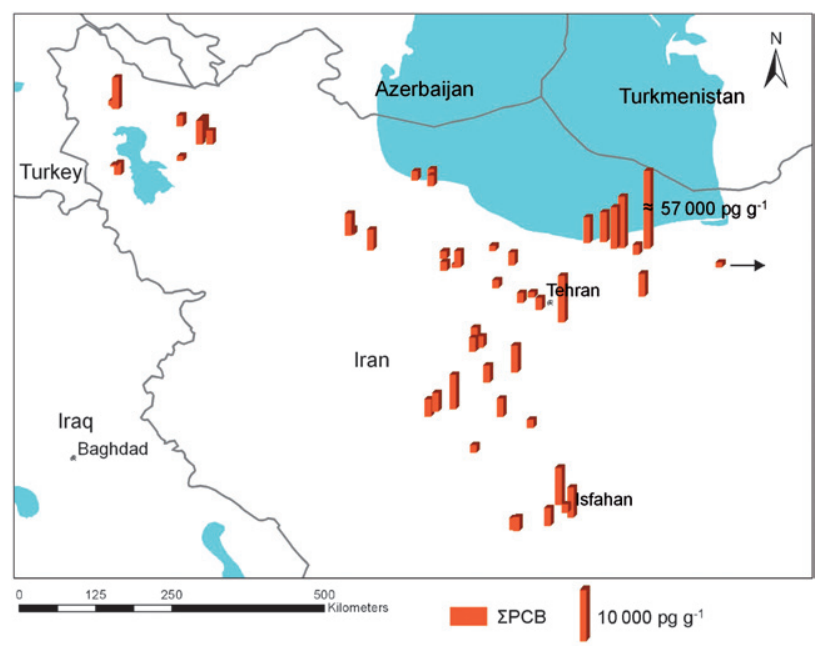

Fig. 3 PCBs in the Iranian butter samples.

\section{Conclusions}

Regarding organochlorine pesticides in Iran, high levels of DDT and its metabolites in rural areas indicate mainly agricultural use of this substance, while HCHs have probably been used for both agricultural and non-agricultural purposes, as no clear urbanrural difference could be observed. In central Iran, the region with the highest DDT concentrations, relatively low DDT/DDE ratios indicate extensive use of this pesticide in the past, still supplying the region with high levels, probably predominantly by volatilisation from contaminated soils. Comparing levels of $\alpha$ - and $\gamma-\mathrm{HCH}$ in Iranian butter samples with a global average, ${ }^{8}$ past and present application of technical $\mathrm{HCH}$ mixtures in Iran seems to be rather low, compared to other parts of the world. HCB showed a homogenous distribution with relatively low concentrations throughout the study area. It is therefore believed to originate mainly from other countries/regions, reaching Iran by atmospheric transport, a process that is very effective in distributing $\mathrm{HCB}$ widely, due to the compound's relatively high vapour pressure and high persistence. ${ }^{21}$

Even though Iran is not known for widespread PCB application in the past, total PCB concentrations in butter exceeded a 'global average' previously reported in a butter survey (Table 1). ${ }^{8}$ Highest burdens were found in the most populated and industrialised areas of the country. $\sum$ PCB concentrations decreased from urban to rural areas, a trend that was more pronounced for higher chlorinated congeners than lower chlorinated ones which are more mobile in the atmosphere.

The results of this survey show how butter can act as a biomonitoring tool, to quickly assess the spatial distribution of POPs across a country/region. To our knowledge, this is the first countrywide survey of POPs in the Middle East, a region with very little information on the distribution/concentration of POPs.

\section{Acknowledgements}

Funding for POPs research from the UK Natural Environment Research Council, and from the UK Department of the Environment, Food and Rural Affairs is gratefully acknowledged. We are grateful to David Hughes and Sue Hodson for continued technical support.

\section{References}

1 UNEP, Final Act of the Conference of Plenipotentiaries on The Stockholm Convention On Persistent Organic Pollutants, United Nations Environment Program, Geneva, Switzerland, 2001.

2 UNEP/GEF, Regionally Based Assessment of Persistent Toxic Substances, Europe (Region III) Regional Report, 2002.

3 UNEP/GEF, Regionally Based Assessment of Persistent Toxic Substances, North America (Region II) Regional Report, 2002.

4 UNEP/GEF, Regionally Based Assessment of Persistent Toxic Substances, South East Asia and South Pacific (Region VIII) Regional Report, 2002.

5 UNEP/GEF, Regionally Based Assessment of Persistent Toxic Substances, Indian Ocean (Region VI) Regional Report, 2002.

6 K. C. Jones and J. L. Barber, Sample matrices, site selection and sampling techniques, Proceedings of the UNEP workshop to develop a global POPs monitoring programme to support the effectiveness evaluation of the Stockholm convention, United Nations Environment Program, Geneva, Switzerland, 2003, 185-199. 
7 K. Pozo, T. Harner, F. Wania, D. Muir, K. C. Jones and L. Barrie, Toward a global network for persistent organic pollutants in air: results from the GAPS study, Environ. Sci. Technol., 2006, 40, 4867-4873.

8 O. I. Kalantzi, R. E. Alcock, P. A. Johnston, D. Santillo, R. L. Stringer, G. O. Thomas and K. C. Jones, The global distribution of PCBs and organochlorine pesticides in butter, Environ. Sci. Technol., 2001, 35, 1013-1018.

9 D. Santillo, A. Fernandes, R. Stringer, R. Alcock, M. Rose, S. White, $\mathrm{K}$. Jones and P. Johnston, Butter as an indicator of regional persistent organic pollutant contamination: further development of the approach using polychlorinated dioxins and furans (PCDD/Fs) and dioxin-like PCBs, Food Addit. Contam., 2003, 20, 281-290.

10 A. Schecter, P. Cramer, K. Boggess, J. Stanley and J. R. Olson, Levels of dioxins, dibenzofurans, PCB and DDE congeners in pooled food samples collected in 1995 at supermarkets across the United States, Chemosphere, 1997, 34, 1437-1447.

11 S. M. Waliszewski, R. Villalobos-Pietrini, S. Gómez-Arroyo and R. M. Infanzón, Persistent organochlorine pesticides in Mexican butter, Food Addit. Contam., 2003, 20, 361-367.

12 G. Yentür, A. Kalay and A. B. Öktem, A survey on organochlorine pesticide residues in butter and cracked wheat available in Turkish markets, Nahrung, 2001, 45, 40-42.

13 G. O. Thomas, A. J. Sweetman, R. Lohmann and K. C. Jones, Derivation and field testing of air-milk and feed-milk transfer factors for PCBs, Environ. Sci. Technol., 1998, 32, 3522-3528.

14 G. O. Thomas, A. J. Sweetman and K. C. Jones, Input-output balance of polychlorinated biphenyls in a long-term study of lactating dairy cows, Environ. Sci. Technol., 1999, 33, 104-112.

15 A. Çok, B. L. Karakaya, B. L. Afkham and S. Burgaz, Organochlorine pesticide contaminants in human milk samples collected in Tebriz (Iran), Bull. Environ. Contam. Toxicol., 1999, 63, $444-450$.
16 T. Krauss, A. M. C. B. Braga, J. M. Rosa, K. Kypke and R. Malisch, Levels of organochlorine pesticides in Brazilian human milk, Organohalogen Compd., 2004, 66, 2773-2778.

17 S. Morisawa, A. Kato, M. Yoneda and Y. Shimada, The dynamic performances of DDTs in the environment and Japanese exposure to them: a historical perspective after the ban, Risk Anal., 2002, 22, $245-263$.

18 J. M. Aislabie, N. K. Richards and H. L. Boul, Microbial degradation of DDT and its residues - a review, N. Z. J. Agr. Res., 1997, 40, 269-282.

19 G. F. Fries, G. S. Marrow and C. H. Gordon, Comparative excretion and retention of DDT analogs by dairy cows, J. Dairy Sci., 1969, 52, $1800-1805$.

20 F. W. Kutz, P. H. Wood and D. P. Bottimore, Organochlorine pesticides and polychlorinated biphenyls in human adipose tissue, Rev. Environ. Contam. Toxicol., 1991, 120, 1-82.

21 J. L. Barber, A. J. Sweetman, D. van Wijk and K. C. Jones, Hexachlorobenzene in the global environment: emissions, levels, distribution, trends and processes, Sci. Total Environ., 2005, 349, 1-44.

22 F. M. Jaward, N. J. Farrar, T. Harner, A. J. Sweetman and K. C. Jones, Passive air sampling of PCBs, PBDEs, and organochlorine pesticides across Europe, Environ. Sci. Technol., 2004, 38, $34-41$.

23 T. Gouin, T. Harner, G. L. Daly, F. Wania, D. Mackay and K. C. Jones, Variability of concentrations of polybrominated diphenyl ethers and polychlorinated biphenyls in air: implications for monitoring, modeling and control, Atmos. Environ., 2005, 39, $151-166$.

24 T. Harner, M. Shoeib, M. Diamond, G. Stern and B. Rosenberg, Using passive air samplers to assess urban-rural trends for persistent organic pollutants. 1. Polychlorinated biphenyls and organochlorine pesticides, Environ. Sci. Technol., 2004, 38, 4474-4483. 